\title{
Chromosome studies in systemic sclerosis with consideration of antibodies to topoisomerase I
}

\author{
Gregory J Tsay, Joung-Liang Lan, Shuan-Yow Li
}

Department of

Medicine,

Chung Shan Medical

and Dental College,

Taichung, Taiwan,

Republic of China

G J Tsay

Cytogenetics

Laboratory,

Chung Shan

Medical and

Dental College,

Taichung, Taiwan,

Republic of China

$\mathrm{S}-\mathrm{Y} \mathrm{Li}$

Division of

Allergy, Immunology,

and Rheumatology,

Department of Medicine,

Taichung Veterans

General Hospital,

Taiwan, Republic

of China

J-L Lan

Correspondence to:

Dr G J Tsay,

Department of Medicine

Chung Shan Medical

and Dental College,

23 Section 1 ,

Taichung Kang Road,

Taichung, Taiwan,

Republic of China

Accepted for publication

13 September 1991

\begin{abstract}
Chromosome studies were performed on 11 patients with systemic sclerosis and on 35 control subjects. Nine patients with systemic sclerosis were positive for antibodies to topoisomerase I and two were negative. Of the 1100 metaphases from these 11 patients, $171(15.5 \%)$ had chromosome breaks, compared with 61 of $3500(1.7 \%)$ metaphases from normal control subjects. There were no statistically significant differences in the numbers of chromosome breaks between men and women. The most common fragile site in patients with systemic sclerosis was at 3p14. The karyotype of all patients was normal. Chromosome breaks did not correlate with the presence of antibodies to topoisomerase $I$.
\end{abstract}

Systemic sclerosis is a systemic autoimmune disease characterised by microvascular lesions and abnormalities of the immune system leading to fibrosis of the skin and certain target organs. The aetiology of systemic sclerosis is unknown. Cytogenetic studies of patients with systemic sclerosis by Emerit and coworkers have shown an increased occurrence of chromosome abnormalities in cell cultures of blood and skin, and aponeurosis. ${ }^{12}$ These findings have been confirmed by other workers. ${ }^{3-5}$ It has been suggested that a chromosome breakage factor is present in the serum of patients with systemic sclerosis. ${ }^{6}$ The chromosomal abnormalities observed in dividing cells are correlated with the breakage factor in serum samples from patients. In addition, autoantibodies directed against DNA topoisomerase I in serum samples from patients with systemic sclerosis have been described by several workers. ${ }^{7-10}$ In human cells, there are two distinct types of DNA topoisomerase in all organisms. ${ }^{11}$ DNA topoisomerase $\mathrm{I}$ is a 100 kilodalton monomeric protein capable of relaxing negative and positive superhelical twist DNA by making transient single strand breaks, whereas topoisomerase II introduces transient double strand DNA breaks. The two enzymes take part in a number of vital processes, including replication, transcription, genetic recombination, and chromosomal decondensation. ${ }^{12}$ Taken together, these observations suggested a study of whether the chromosomal abnormalities are related to the presence of the antibody to topoisomerase $I$ in patients with systemic sclerosis. Our results suggest that the chromosomal abnormalities are not correlated with the presence of the antibody to topoisomerase I. The chromosomal region at $3 \mathrm{pl} 14$ tends to be the most common fragile site in patients with systemic sclerosis.
Patients and methods

PATIENTS WITH SYSTEMIC SCLEROSIS

Eleven patients with systemic sclerosis were identified as having diffuse scleroderma with the skin of the proximal portions of the extremities and trunk, or both, affected, as well as fingers, hands, and face (classic scleroderma), according to the preliminary criteria for the diagnosis of systemic sclerosis. ${ }^{13}$ The median age of the 11 patients with scleroderma was 55 years, ranging from 32 to 69 years and the group consisted of six men and five women. None of the patients with systemic sclerosis had received cytotoxic drugs or other drugs known to induce chromosomal changes before the study. Similar studies were performed on 35 control subjects recruited from the hospital and laboratory staff. The control subjects were matched for age and sex. The median age of the 35 control subjects was 57 years, ranging from 28 to 71 years, and there were 18 men and 17 women.

\section{CHROMOSOME ANALYSIS}

A $10 \mathrm{ml}$ sample of blood was obtained from each patient and control subject and three blood cultures were established by injecting $0.5 \mathrm{ml}$ of whole blood into $10 \mathrm{ml}$ of culture medium consisting of $M$ medium (modified F10 medium without thymidine, folic acid, and hypoxanthine, Gibco formula 785227 ) with $4.5 \%$ fetal calf serum, phytohaemagglutinin, and PSN (Gibco antibiotic mixture of penicillin, streptomycin, and neomycin). The cultures were incubated for four days, treated with colcemid $(0 \cdot 1 \mu \mathrm{g} / \mathrm{ml})$ and $0.0075 \mathrm{M}$ hypotonic potassium chloride for 12 minutes, and fixed in a minimum of three changes of methanol/glacial acetic acid (3:1) fixative. Cells in fresh fixative were dropped onto a clean slide. The slides were air dried and stained with Giemsa. All cultures were handled by the same technician. A minimum of $100 \mathrm{G}$ banded metaphases from each subject was selected at random and photographed under $1000 \times$ magnification and scored for structural chromosomal abnormalities.

\section{ANTIBODY TO TOPOISOMERASE I}

All samples were screened for antibody to topoisomerase I using a previously described technique. ${ }^{9}$ Briefly, DNA topoisomerase I was purified from calf thymus as an antigen. Serum samples from patients and control subjects were diluted 1:200 and screened for the antibody to topoisomerase I by an enzyme linked immunosorbent assay (ELISA). 


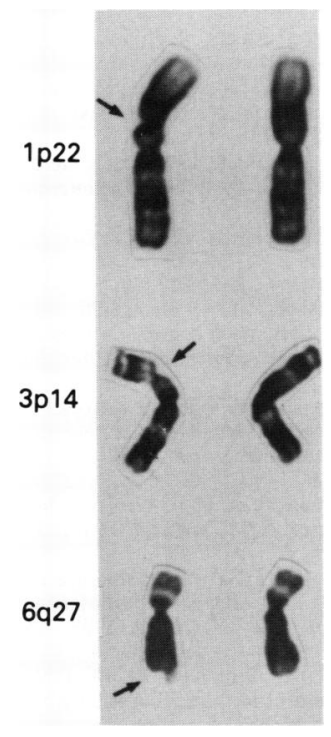

Figure 1 Examples of chromosome breakage. Arrows indicate breakage points.

Table 1 Comparison of chromosome breakage in patients with systemic sclerosis and normal control subjects

\begin{tabular}{llllll}
\hline Subject & $\begin{array}{l}\text { No of } \\
\text { metaphases }\end{array}$ & $\begin{array}{l}\text { Chromosome } \\
\text { breakage }\end{array}$ & p Value & $\begin{array}{l}\text { Breakage at } \\
3 p 14\end{array}$ & $p$ Valuet \\
\hline $\begin{array}{l}\text { Systemic sclerosis }(\mathrm{n}=11) \\
\text { Normal }(\mathrm{n}=35)\end{array}$ & 1100 & 171 & $<0.001$ & 62 & $<0.001$ \\
\hline
\end{tabular}

${ }^{*} \mathrm{p}$ Value based on $\chi^{2}$ test between all chromosome breakages in patients with systemic sclerosis and normal control subjects. tp Value based on $\chi^{2}$ test breakage at 3 pl4 between patients with systemic sclerosis and normal control subjects.

\section{Results}

Figure 1 gives an example of a metaphase showing chromosome breakage. The results of the cytogenetic observations in the 11 patients with systemic sclerosis compared with those in the 35 normal control subjects are given in Table 1. Of the 1100 metaphases from these 11 patients, $171(15.5 \%)$ of the metaphases had chromosome breaks, compared with 61 (1.7\%) of the 3500 metaphases from normal control subjects. The overall occurrence of structural chromosome breakages was significantly increased $(p<0.001)$ in patients with systemic sclerosis. Chromosome breaks were found in 88 of 600 metaphases from six male patients and 83 of 500 metaphases from five female patients. There were no statistically significant differences between the numbers of chromosome breaks in male and female patients.

The distribution of chromosome breakage sites in all patients was analysed. The numbers of lesions at different chromosomal sites are shown in table 2. Of a total 171 chromosome breaks from patients with systemic sclerosis, 62 breaks were at $3 \mathrm{p} 14$, compared with only seven $(0 \cdot 2 \%)$ of 3500 metaphases from normal control subjects. Chromosome breaks at 3p14 were 28 times more common in patients with systemic sclerosis than in normal control subjects. The chromosome region at 3pl4 was the most common fragile site in patients with systemic sclerosis.

Figure 2 shows the relation of the antibody to topoisomerase I and chromosome breaks in patients with systemic sclerosis. The cut off points for the significantly increased levels of antibodies to topoisomerase I were determined on the basis of 21 healthy control subjects. ${ }^{9}$ The normal mean (SD) value of the absorbance was $0.406(0.173)$. Values above 0.925 (normal value plus three SD) were regarded as increased levels of antibodies to topoisomerase I. The occurrence of the antibody to topoisomerase $\mathbf{I}$ in our patients with systemic sclerosis was $8 / 11(73 \%)$ by ELISA. No close correlation between the presence of the antibody to topoisomerase I and chromosome breaks in patients with systemic sclerosis was found $(r=0 \cdot 77, p>0 \cdot 05)$.

Table 2 Occurrence of chromosome lesion sites in 11 patients with systemic sclerosis

\begin{tabular}{ll}
\hline Lesion sites & Total no of breakages \\
\hline $3 \mathrm{p} 14$ & 62 \\
$6 \mathrm{q} 27$ & 8 \\
$10 \mathrm{q} 22$ & 7 \\
$8 \mathrm{q} 22$ & 4 \\
$2 \mathrm{p} 13$ & 3 \\
$2 \mathrm{p} 22$ & 3 \\
$2 \mathrm{q} 24$ & 3 \\
$10 \mathrm{q} 22$ & 3 \\
$10 \mathrm{q} 23$ & 3 \\
\hline
\end{tabular}



Figure 2 Antibody to topoisomerase I measured by an enzyme linked immunosorbent assay (ELISA) was read at $405 \mathrm{~nm}$. The presence of antibody to topoisomerase I did not correlate with chromosome breakage in patients with systemic sclerosis $(p>0.05)$.

\section{Discussion}

Our data provide additional confirmation that there is an increased occurrence of chromosome breaks in patients with systemic sclerosis. Although chromosome breaks are common in patients with systemic sclerosis, the common chromosome regions prone to breakage in these patients have not previously been reported. We found that the most common fragile site in patients with systemic sclerosis is $3 p 14$. Previously Smeets et $a l^{14}$ reported that 3 pl4 was the region most prone to breakage in normal human chromosomes. The chromosome region at 3 p14 seems to be the fragile site in normal subjects and in patients with systemic sclerosis. Several workers ${ }^{15} 16$ have suggested that fragile sites play a preferential part in the chromosome translocations that are associated with certain diseases. The clinical significance of the fragile site in patients with systemic sclerosis is not clear.

It has been suggested that patients with systemic sclerosis may possess a serum clastogen and could induce chromosome breakage. ${ }^{6}$ Although the serum factor has not been isolated or identified, its presence in patients' serum indicates that scleroderma associated chromosome breakage has a molecular basis. Topoisomerase I has been associated with chromosomal decondensation and genetic recombination. ${ }^{11} 12$ Patients with diffuse scleroderma often have antibodies to topoisomerase I and high titres of the antibody to topoisomerase I are mostly present in patients with diffuse scleroderma. ${ }^{9}$ An evaluation of the relations between antibodies to topoisomerase I and chromosome breakage was included in this study. We found that there was no correlation 
between the presence of antibodies to topoisomerase I and chromosome breakage in patients with diffuse scleroderma. The occurrence of chromosome abnormalities among our patients who were positive for antibodies to topoisomerase I were similar to those in patients who were negative for such antibodies. Thus antibodies to topoisomerase $I$ in patients with systemic sclerosis do not appear to be the chromosome breakage factor. Powell et al reported that the anticentromere antibody which is also present in patients with a variant form of systemic sclerosis does not appear to have clastogenic properties in vitro. ${ }^{17}$ The biochemical nature of the breakage factors remain unclear at present and need further investigation.

We thank Chin-Chu Tsai for her excellent technical assistance. This study was partly supported by grant NSC 79-0412-B040-04 from National Science Council, Taiwan, Republic of China.

1 Emerit I, Housset E, de Grouchy J, Camus J P. Chromosomal breakage in diffuse scleroderma: a study of 27 patients. Biomedicine 1971; 16: 684-94.

2 Housset E, Emerit I, Baulon A, de Grouchy J. Anomalies chromosomiques dans la sclerodermie generalisee: une chromosomiques dans la sclerodermie generalisee: une

3 Benoit M, Merlen J F, Croquette-Bulteel M F. Interet du caryotype dans le diagnostic differentiel des stats sclerodermiqsues. Bulletin de la Société Française de Dermatologie et de Syphiligraphie 1973; 640: 636-40.

4 Pan S F, Rodnan G P, Deutsch M, Wald N. Chromosomal abnormalities in progressive systemic sclerosis (scleroderma) with consideration of radiation effects. $\mathcal{F}$ Lab Clin Med 1975; 86: 300-8.

5 Sherer G K, Jackson B B, Leroy E C. Chromosome breakage and sister chromatid exchange frequencies in scleroderma Arthritis Rheum 1981; 24: 1409-1418.

6 Emerit I, Levy A, Housset E. Breakage factor in systemic sclerosis and protector effect of L-cysteine. Humangentik 1974; 25: 221-6.

7 Shero J H, Bordwell B, Rothfield N F, et al. High titers of autoantibodies to topoisomerase I (Scl-70) in sera from scleroderma patients. Science 1986; 231: 737-40.

8 Gouldner H, Szostecki C, Vosberg H, et al. Scl-70 autoantibodies from scleroderma patients recognize a $95 \mathrm{KDa}$ protein as DNA topoisomerase I. Chromosoma 1986; 94: 132-8.

9 Tsay G J, Fann R-H, Hwang J. Specificity of anti-Scl-70 antibodies in scleroderma: increased sensitivity of detection using purified DNA topoisomerase I from calf thymus. using purified DNA topoisomer

10 Tan E M. Autoantibodies to nuclear antigens (ANA): their immunobiology and medicine. Adv Immunol 1982; 33: 167-240.

11 Juan C C, Hwang J, Liu A. Human DNA topoisomerase I is encoded by single-copy gene that maps to chromosome region 20q12-13.2. Proc Natl Acad Sci USA 1988; 85. region 20 - 13.

12 Zhang $\mathrm{H}$, Wang J C, Liu L F. Involvement of DNA topoisomerase I in transcription of human ribosomal RNA genes. Proc Natl Acad Sci USA 1988; 85: 1060-4.

13 Subcommittee for Scleroderma Criteria of the American Rheumatism Association Diagnostic and Therapeutic Criteria Committee. Preliminary criteria for the classification of systemic sclerosis (scleroderma). Arthritis Rheum 1980; 23: $581-90$.

14 Smeets D F C M, Scheres J M J C, Hustinx T W J. The most common fragile site in man is 3p14. Hum Genet 1986; 72: 215-20.

15 Whang-Peng J, Kao-Shan C S, Lee E C. Specific chromosome defect associated with human small-cell lung cancer: deletion 3p(14-23). Science 1982; 215: 181-2.

16 Yunis J J, Soreng A L. Constitutive fragile sites and cancer. Science 1984; 226: 1199-204.

17 Powell F C, Schroeter A L, Winkelmann R K, et al. Chromosome studies in scleroderma with consideration of anticentromere antibody status and assessment of possible in vitro clastogenic activity. Acta Derm Venereol (Stockh) 1986; 66: 414-8. 